\title{
Hyperthermophiles in the history of life
}

\author{
Karl O. Stetter* \\ University of Regensburg, Universitätsstrasse 31, 93053 Regensburg, Germany
}

\begin{abstract}
Today, hyperthermophilic ('superheat-loving') bacteria and archaea are found within hightemperature environments, representing the upper temperature border of life. They grow optimally above $80^{\circ} \mathrm{C}$ and exhibit an upper temperature border of growth up to $113^{\circ} \mathrm{C}$. Members of the genera, Pyrodictium and Pyrolobus, survive at least $1 \mathrm{~h}$ of autoclaving. In their basically anaerobic environments, hyperthermophiles (HT) gain energy by inorganic redox reactions employing compounds like molecular hydrogen, carbon dioxide, sulphur and ferric and ferrous iron. Based on their growth requirements, HT could have existed already on the early Earth about 3.9 Gyr ago. In agreement, within the phylogenetic tree of life, they occupy all the short deep branches closest to the root. The earliest archaeal phylogenetic lineage is represented by the extremely tiny members of the novel kingdom of Nanoarchaeota, which thrive in submarine hot vents. HT are very tough survivors, even in deep-freezing at $-140^{\circ} \mathrm{C}$. Therefore, during impact ejecta, they could have been successfully transferred to other planets and moons through the coldness of space.
\end{abstract}

Keywords: archaea; hyperthermophiles; origin of life

\section{INTRODUCTION}

The first traces of life on Earth date back to the Early Archaean, between 3.5 and 3.9 Gyr ago. Although the recognition of ancient microfossils just by morphology turned out to be very difficult, there are chemical traces of life within the rocks from Precambrian deep-sea vents (Schopf \& Packer 1987; Brasier et al. 2002; van Zullen et al. 2002). These had been the times at the end of the heavy meteorite bombardment. The surface of the early Earth must have been much hotter than today. Expelled by impacts, microbes could have spread in between the planets and moons of the early Solar System. Only superheat-loving microbes similar to the hyperthermophiles (HT; Stetter 1992) would have been able to thrive and survive in such an 'early times of life' scenario. Twenty-five years ago, the first HT had been isolated, which exhibited unprecedented optimal growth temperatures above $80^{\circ} \mathrm{C}$, where usual mesophilic and thermophilic bacteria are killed within seconds (Brock 1978; Stetter et al. 1981; Zillig et al. 1981; Stetter 1982). HT turned out to be very common in hot terrestrial and submarine environments. Their position within the universal phylogenetic tree of life provides further strong evidence of a hyperthermophilic last common ancestor (see subsequently). In my research, I am looking for today's HT, their environments, properties and modes of living. So far, I have been collecting more than 1500 strains of HT. These include isolates that even survive autoclaving at $121^{\circ} \mathrm{C}$. The question as to whether such organisms at $121^{\circ} \mathrm{C}$ are still slowly growing or just surviving is still unanswered (Blöchl et al. 1997; Kashefi \& Lovley 2003; Cowan 2004).

\section{*karl.stetter@biologie.uni-regensburg.de}

One contribution of 19 to a Discussion Meeting Issue 'Conditions for the emergence of life on the early Earth'.

\section{PHYLOGENETIC RELATIONSHIPS OF HT}

Based on the pioneering work of Carl Woese, the small subunit ribosomal RNA (ss rRNA) is widely used in phylogenetic studies (Woese \& Fox 1977; Woese et al. 1990). In Bacteria and Archaea it consists of about 1500 bases. Owing to sequence comparisons, a phylogenetic tree is now available (figure 1). It shows a tripartite division of the living world into the bacterial, archaeal and eukaryal domains. Within this tree, deep branches are evidenced for early separation. The separation of the bacteria from the stem shared by Archaea and Eukarya represents the deepest and earliest branching point. Short phylogenetic branches indicate a rather slow rate of evolution. In contrast to the Eukarya, the bacterial and archaeal domains within the phylogenetic tree exhibit some extremely short and deep branches. Surprisingly, these are covered exclusively by HT, which therefore form a cluster around the phylogenetic root (figure 1, thick lineages). The deepest and shortest phylogenetic branches are represented by the Aquificales and Thermotogales within the bacteria and the Nanoarchaeota, Pyrodictiaceae and Methanopyraceae within the Archaea, indicating a slow rate of evolution. Now, several total genome sequences are already available. Within the sequences, as a rule, trees based on genes involved in information management (e.g. DNA replication, transcription, translation) parallel the ss rRNA tree. However, within the genes of metabolism, based on the frequent lateral gene transfer, a network rather than a tree may reflect their phylogenetic relations (Doolittle 1999).

At present, about 90 species of hyperthermophilic archaea and bacteria are known, which had been isolated from different terrestrial and marine thermal areas in the world. HT are very divergent, in terms of both their phylogeny and physiological properties and are grouped into 34 genera and 10 orders. 


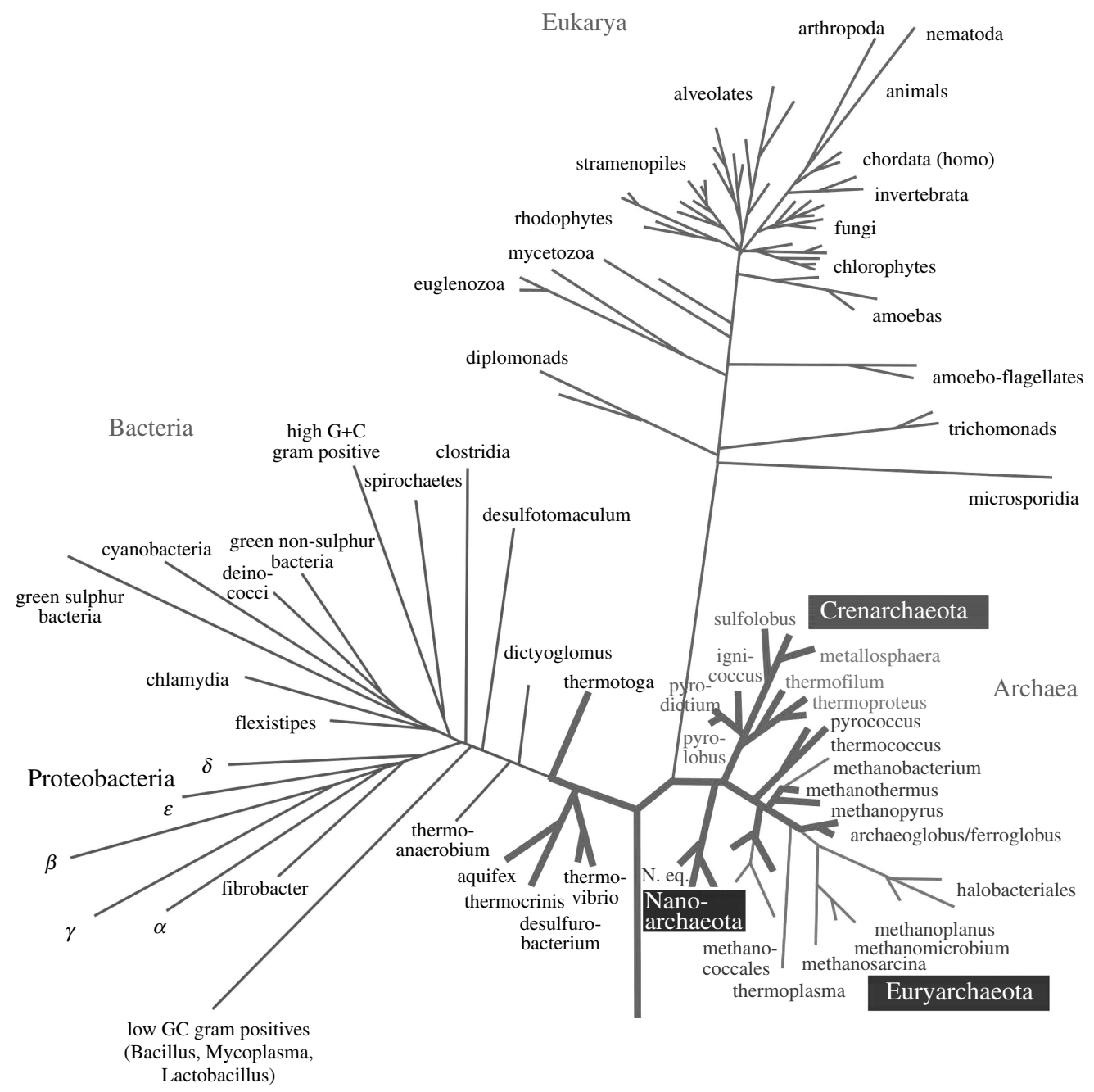

Figure 1. Small subunit ribosomal RNA-based phylogenetic tree. The thick lineages represent HT.

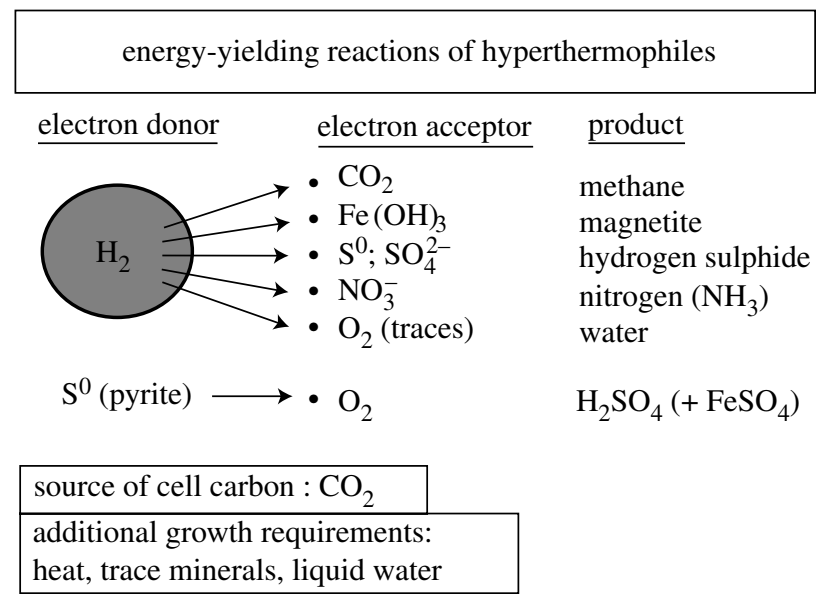

Figure 2. Schematic of main energy-yielding reactions in chemolithoautotrophic HT.

\section{ENERGY SOURCES AND LIFESTYLE}

The energy sources of HT are very simple. Most species exhibit a chemolithoautotrophic mode of nutrition (figure 2). Anaerobic and aerobic types of respiration follow inorganic redox reactions (chemolithotrophic), and $\mathrm{CO}_{2}$ is the only carbon source required to build-up organic cell material (autotrophic). Therefore, these organisms fix $\mathrm{CO}_{2}$ by chemosynthesis and are designated chemolithoautotrophs. Molecular hydrogen serves as an

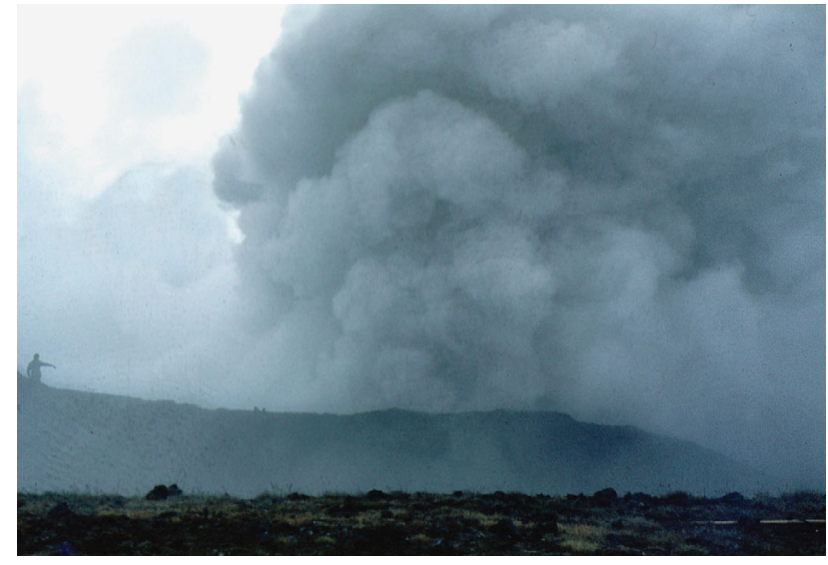

Figure 3. Krafla solfataric field (Iceland), 2 days before a volcanic fissure eruption. A huge fumarole throws up lumps of boiling mud that contained viable HT.

important electron donor. Other electron donors are sulphide, sulphur and ferrous iron. As in mesophilic respiratory organisms, in some HT, oxygen may serve as an electron acceptor. However, in contrast, oxygenrespiring HT are usually microaerophilic and therefore grow only at reduced oxygen concentrations. Anaerobic respiration types are the nitrate, sulphate, sulphur and carbon dioxide respirations. While chemolithoautotrophic HT produce organic matter, there are some HT that depend on organic material as energy and carbon 


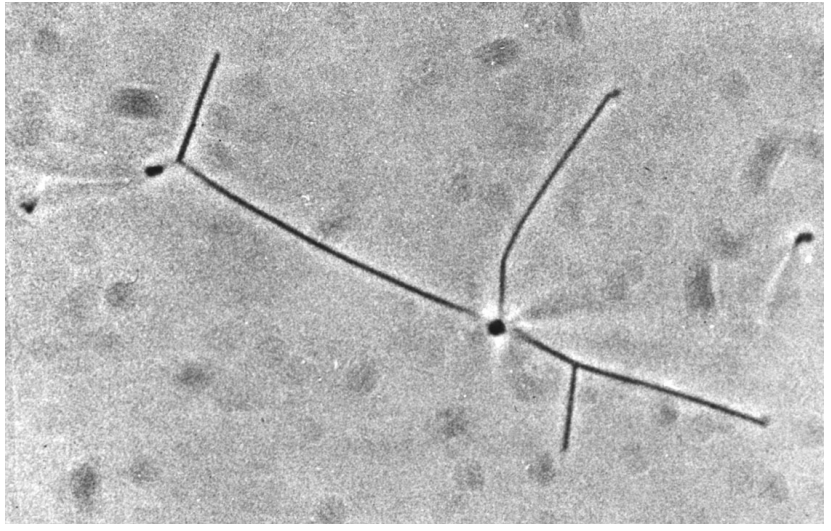

Figure 4. Antler-shaped cell of Thermoproteus, about $100 \mu \mathrm{m}$ in length and $0.4 \mu \mathrm{m}$ in diameter. Phase-contrast light micrograph.

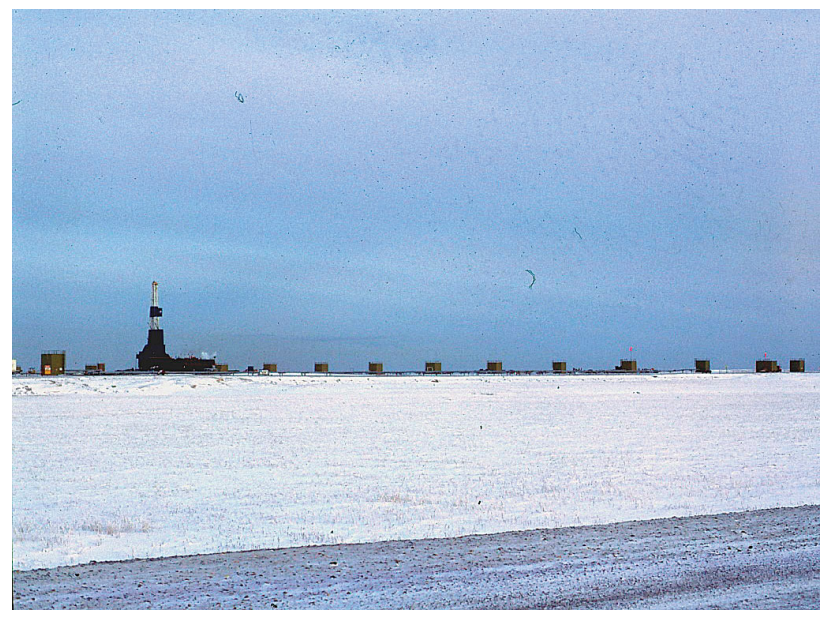

Figure 5. Oil wells within the permafrost soil at Prudhoe Bay, North Alaska.

sources. They are designated as heterotrophs. Several chemolithoautotrophic HT are opportunistic heterotrophs. These are able to use organic material alternatively to inorganic nutrients, whenever it is provided by the environment (e.g. by decaying cells). Heterotrophic HT gain energy either by aerobic or different types of anaerobic respiration, using organic material as electron donor or by fermentation.

HT are adapted to distinct environmental factors including composition of minerals and gasses, $\mathrm{pH}$, redox potential, salinity and temperature. Similar to mesophiles, they grow within a temperature range of about $25-30^{\circ} \mathrm{C}$ between the minimal and maximal growth temperature. Fastest growth is obtained at their optimal growth temperature, which may be up to $106^{\circ} \mathrm{C}$. As a rule, $\mathrm{HT}$ do not propagate at $50^{\circ} \mathrm{C}$ or below. HT are very tough survivors. Although unable to grow at ambient temperatures and space temperatures of $-140^{\circ} \mathrm{C}$, they are able to survive there for many years. Based on their simple growth requirements, HT could grow on any hot water-containing site, even on other planets and moons like Mars and Europa. Today, the surface of Mars is too cold and contains no liquid water and is therefore hostile to life. However, in a depth of a few kilometres below the permafrost layer, there may be hot liquid water and nutrients to support the growth of HT even today. Microbial life could have colonized Mars via meteorites, about 4 Gyr ago. At that

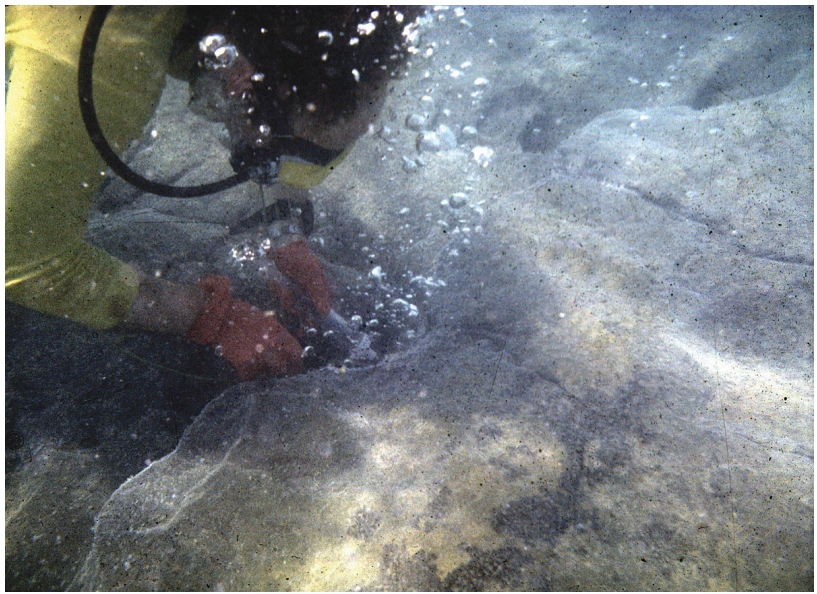

Figure 6. Sampling at the submarine hydrothermal vents at Porto di Levante, Vulcano (Italy). Hot water and gas escape from cracks within hot volcanic rocks.

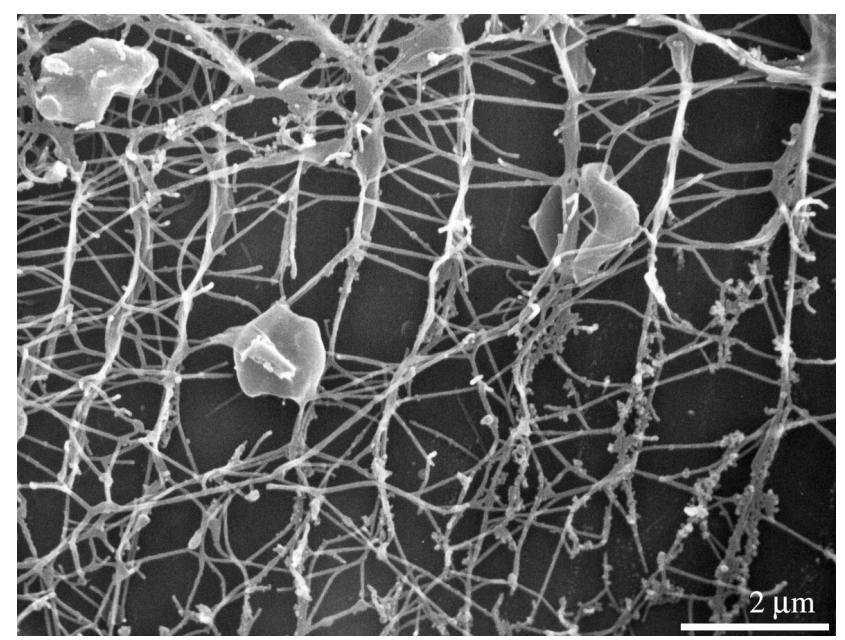

Figure 7. Pyrodictium abyssi, disk-shaped cells within a network of ultrathin tubules. Scanning electron micrograph.

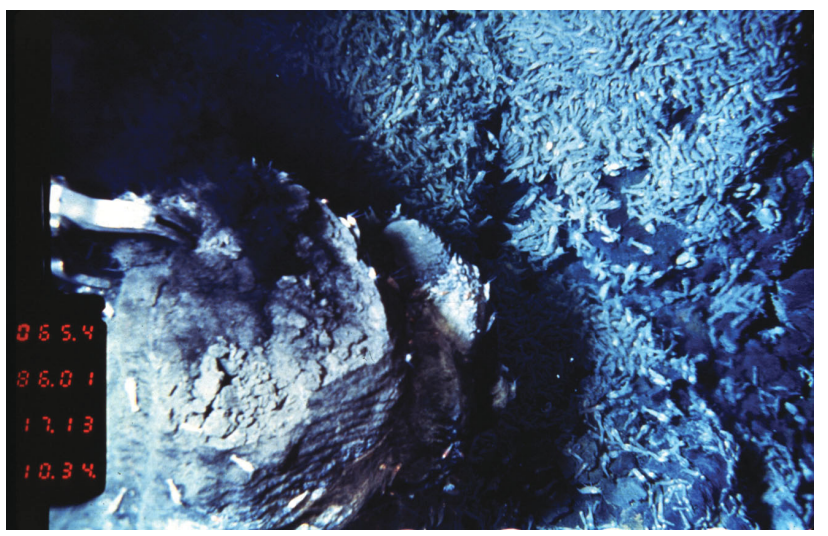

Figure 8. Sampling of hot rocks from a 'Beehive Smoker' at the Mid-Atlantic Ridge (TAG site; $21^{\circ} \mathrm{N}$; depth approx. $4000 \mathrm{~m})$.

time, the surface of Mars contained liquid water and perhaps harboured hydrothermal systems, therefore being favourable to HT.

\section{BIOTOPES}

HT form complex communities within watercontaining geothermally and volcanically heated 
environments situated mainly along the terrestrial and submarine tectonic spreading and the subduction zones. The availability of liquid water is a fundamental prerequisite of life. At an increased boiling point of water (for example, by elevated atmospheric, hydrostatic or osmotic pressure), several HT exhibit growth temperatures exceeding $100^{\circ} \mathrm{C}$. Owing to the presence of reducing gases like $\mathrm{H}_{2} \mathrm{~S}$ and the low solubility of $\mathrm{O}_{2}$ at high temperatures, the biotopes of HT are virtually oxygen-free (anaerobic). HT have been isolated from terrestrial and submarine environments.

Natural terrestrial biotopes of HT are mainly hot springs and sulphur-containing solfataric fields, with a wide range of $\mathrm{pH}$ values $(\mathrm{pH}$ 0-9.0) and usually low salinity $(0.1-0.5 \%)$. Solfataric fields consist of soils, mud holes and surface waters, heated by volcanic exhalations from magma chambers several kilometres below. Very often, solfataric fields are found close to active volcanoes and the activity is greatly increased during eruption phases (figure 3). Within the boiling mud, under our field microscope, we found up to $10^{7}$ per gram of antler-shaped giant cells, members of the novel genus Thermoproteus (figure 4; Zillig et al. 1981). The chemical composition of solfataric fields is very variable and depends on the site. Many of them are rich in iron minerals like ferric hydroxides and pyrite. Less common compounds like magnetite and the arsenic minerals, realgar and auripigment, may be enriched at some sites, for example in Caldera Uzon, Kamchatka. Steam within the solfataric exhalations is mainly responsible for the heat transfer. In addition, they may contain carbon dioxide, variable amounts of $\mathrm{H}_{2}$, methane, nitrogen, carbon monoxide and traces of nitrate and ammonia. Hydrogen may be formed either pyrolytically from water or chemically from $\mathrm{FeS}$ and $\mathrm{H}_{2} \mathrm{~S}$ (Drobner et al. 1990). Other suitable biotopes for HT are deep subterranean, geothermally heated oil stratifications, about $3500 \mathrm{~m}$ below the bottom of the North Sea and the surface of the permafrost soil at the North Slope, Northern Alaska (figure 5; Stetter et al. 1993). The produced fluids contained up to $10^{7}$ viable cells per litre of different species of HT such as Archaeoglobus and Pyrococcus. Artificial biotopes include smouldering coal refuse piles and hot outflows from geothermal power plants.

Submarine biotopes of HT consist of various hydrothermal systems situated at shallow to abyssal depths. Similar to ambient seawater, submarine hydrothermal systems usually contain high concentrations of salt and exhibit a slightly acidic to alkaline $\mathrm{pH}$ (5-8.5). The major gasses and life-supporting mineral nutrients may be similar to those within the terrestrial thermal areas. Shallow submarine hydrothermal systems are found in many parts of the world, mainly on beaches with active volcanism. The hot vents at Vulcano, Italy, exhibit temperatures of $80-105^{\circ} \mathrm{C}$ (figure 6). Within these, I discovered life above $100^{\circ} \mathrm{C}$ (Stetter 1982): Pyrodictium occultum grows fastest at $105^{\circ} \mathrm{C}$ and exhibits an upper temperature border of growth at $110^{\circ} \mathrm{C}$. Members of Pyrodictium form networks of disk-shaped cells connected by ultra thin tubules (figure 7). The finding of Pyrodictium disproved the prejudice about marine thermophiles being less

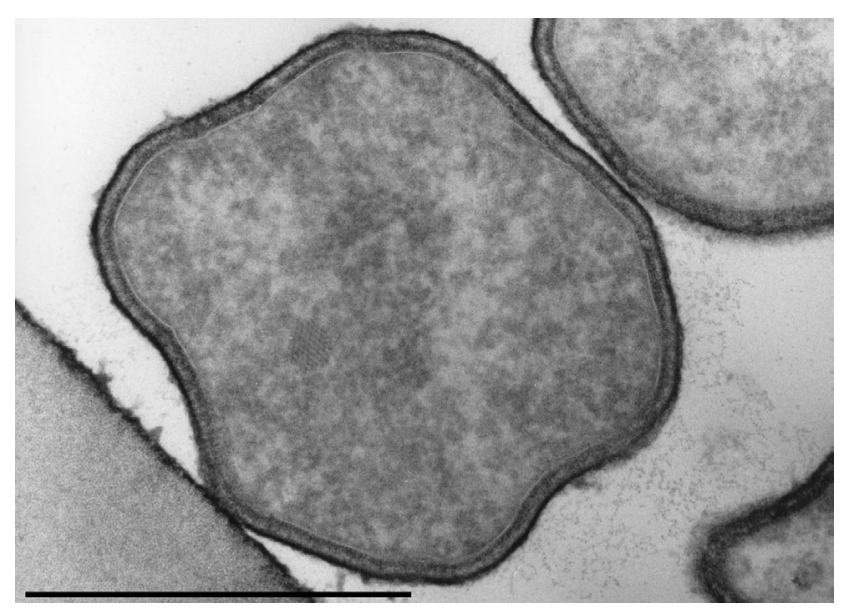

Figure 9. Pyrolobus fumarii, lobed coccoid cell. Ultrathin section. Transmission electron micrograph. Scale bar, $0.5 \mu \mathrm{m}$.

thermophilic than those from terrestrial environments (Castenholz 1979).

Most impressive are the deep sea 'smoker' vents, where mineral-laden hydrothermal fluids with temperatures up to about $400^{\circ} \mathrm{C}$ escape into the cold $\left(2.8^{\circ} \mathrm{C}\right)$, surrounding deep seawater and build-up huge rock chimneys. Although these hot fluids are sterile, the surrounding porous smoker rock material appears to contain very steep temperature gradients, which provide zones of suitable growth temperatures for HT. Some smoker rocks are teeming with HT. For example, $10^{8}$ cells of Methanopyrus per gram of rock were found in a mid-Atlantic 'beehive' hot vent chimney (figure 8). Another type of submarine hightemperature environment is provided by active sea mounts. Close to Tahiti, there is a huge abyssal volcano, Macdonald Seamount (28 $58.7^{\prime}$, $\left.140^{\circ} 15.5^{\prime} \mathrm{W}\right)$, the summit of which is situated approximately $40 \mathrm{~m}$ below the sea surface. The samples taken during an active phase from the submarine eruption plume and rocks from the active crater contained high concentrations of viable HT (Huber et al. 1990).

\section{EXAMPLES OF RECENT HYPERTHERMOPHILIC ARCHAEA}

From the walls of a black smoker at the Mid-Atlantic Ridge, we had isolated the archaeon, Pyrolobus fumarii (Blöchl et al. 1997). Cells are lobed cocci of about $0.7-2.5 \mu \mathrm{m}$ in diameter (figure 9). Pyrolobus fumarii is optimally adapted to temperatures of superheated water, exhibiting an optimal growth temperature of $106^{\circ} \mathrm{C}$ and an upper temperature border of growth at $113^{\circ} \mathrm{C}$. It is so dependent on high temperatures that it is unable to grow below $90^{\circ} \mathrm{C}$. The cultures of $P$. fumarii, similar to $P$. occultum, are able to survive autoclaving for $1 \mathrm{~h}$ at $121^{\circ} \mathrm{C}$. Finally, I want to introduce the phenotype and genotype of a member of a novel group of hyperthermophilic virus-sized archaea, which may have already existed at the dawn of life and had been completely overlooked so far. From a submarine hydrothermal system at the Kolbeinsey Ridge, North of Iceland, we were able to obtain our ultimate hyperthermophilic coccoid isolate Nanoarchaeum 


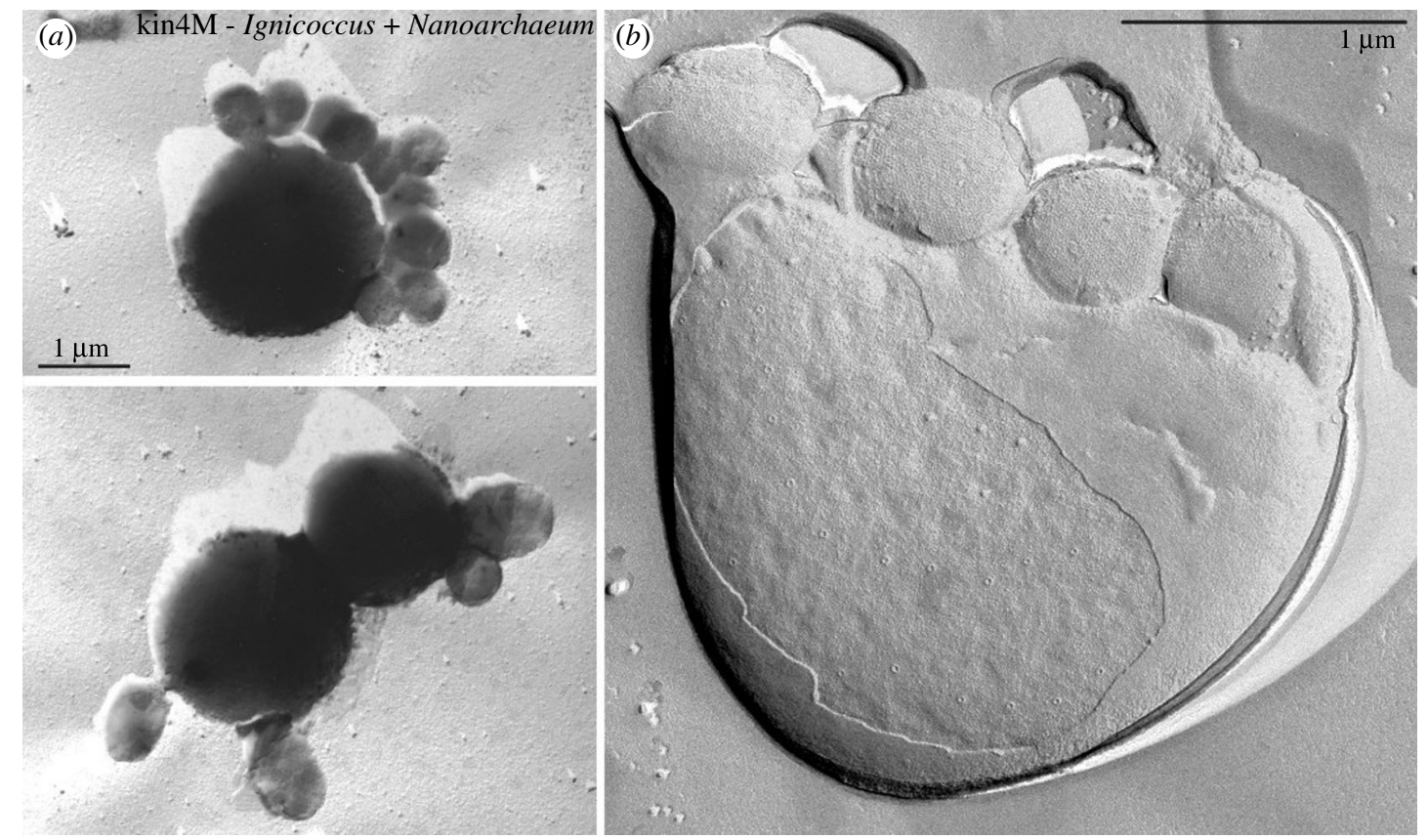

Figure 10. Cells of $N$. equitans (small) attached to Ignicoccus strain Kin 4M (large). (a) Platinum-shadowing. (b) Freeze-etching. Transmission electron micrographs.

equitans, which represents a novel kingdom of Archaea (Huber et al. 2002). It is the smallest living organism known with a cell diameter of only $400 \mathrm{~nm}$. Cells grow attached to the surface of a specific crenarchaeal host, a new member of the genus Ignicoccus (figure 10). Owing to their unusual ss rRNA sequence, members of $N$. eqitans remained undetectable by commonly used 'universal' primers in the ecological studies based on the polymerase chain reaction. $N$. equitans represents the most deeply branching position within the Archaea, suggesting that the Nanoarchaeota diverged early within the Archaea (figure 1). The genome of $N$. equitans harbours some big surprises (Waters et al. 2003): with only 490885 base pairs, it is the smallest microbial genome known to date and also the most compact, with $95 \%$ of the DNA predicted to encode proteins or stable RNAs. This genome encodes the complete machinery for information processing and repair, but lacks genes for lipid, cofactor, amino acid and nucleotide biosynthesis. The limited biosynthetic and catabolic capacity of $N$. equitans suggests that its symbiotic relationship to the Ignicoccus host may be parasitic, making it the only known archaeal parasite. However, unlike the small genomes of bacterial parasites that are undergoing reductive evolution, the small genome of $N$. equitans has very few pseudogenes and a well equipped DNA recombination system. In contrast to modern parasites, no free-living relatives of Nanoarchaeum could be detected so far. Therefore, it may be a very ancient parasite. Alternatively, the Ignicoccus-Nanoarchaeum system may even represent remains from pre-Archaea communities (Kandler 1994). At its molecular level, Nanoarchaeum harbours further unexpected, most probably primitive properties like separately encoded enzyme modules and-for the first time- tRNA gene fragments (Waters et al. 2003; Randau et al. 2005). At present, we are still far away from a deeper understanding of the NanoarchaeumIgnicoccus relationship and further investigations are required. The Nanoarchaeota inhabit hot environments worldwide. Two ss rRNA sequences from Uzon Caldeira (Kamchatka, Russia) and Yellowstone National Park (USA) exhibit $83 \%$ sequence similarity to $N$. equitans and therefore represent a distinct family within the Nanoarchaeota (Hohn et al. 2002). These novel Nanoarchaeota are again tiny cocci about the size of $N$. equitans, however attached to a different (rod-shaped) Pyrobaculum-like host. The discovery of Nanoarchaeota suggests that further major groups of microbes may still be unrecognized, and are waiting for their isolation to tell us more about the origin and evolution of life.

I thank Reinhard Rachel for electron microscopy and Harald Huber for redrawing the phylogenetic tree. The work presented from my laboratory was supported by grants of the DFG, the BMBF, the EEC and the Fonds der Chemischen Industrie.

\section{REFERENCES}

Blöchl, E., Rachel, R., Burggraf, S., Hafenbradl, D., Jannasch, H. W. \& Stetter, K. O. 1997 Pyrolobus fumarii, gen. and sp. nov., represents a novel group of archaea, extending the upper temperature limit for life to $113^{\circ} \mathrm{C}$. Extremophiles 1, 14-21. (doi:10.1007/s007920050010)

Brasier, M. D., Green, O. R., Jephcoat, A. P., Kleppe, A. K., Van Kranendonk, M. J., Lindsay, J. F., Steele, A. \& Grassineau, N. V. 2002 Questioning the evidence for Earth's oldest fossils. Nature 416, 76-81. (doi:10.1038/416076a)

Brock, T. D. 1978. Thermophilic microorganisms and life at high temperatures, vol. xi. New York, NY: Springer. 465 pp.

Castenholz, R. W. 1979 Evolution and ecology of thermophilic microorganisms. In Strategies of microbial life in extreme environments (ed. M. Shilo), pp. 373-392. Weinheim, Germany: Verlag Chemie.

Cowan, D. A. 2004 The upper limit of life: how far can we go. Trends Microbiol. 12, 58-60. (doi:10.1016/j.tim.2003.12. 002)

DiRuggiero, J., Santangelo, N., Nackerdeen, Z., Ravel, J. \& Robb, F. T. 1997 Repair of extensive ionizing-radiation DNA damage at $95^{\circ} \mathrm{C}$ in the hyperthermophilic archaeon Pyrococcus furiosus. F. Bacteriol. 179, 4643-4645. 
Doolittle, W. F. 1999 Phylogenetic classification and the universal tree. Science 284, 2124-2129. (doi:10.1126/ science.284.5423.2124)

Drobner, E., Huber, H., Wächtershäuser, G., Rose, D. \& Stetter, K. O. 1990 Pyrite formation linked with hydrogen evolution under anaerobic conditions. Nature 346, 742-744. (doi:10.1038/346742a0)

Hohn, M. J., Hedlund, B. P. \& Huber, H. 2002 Detection of $16 \mathrm{~S}$ rDNA sequences representing the novel phylum "Nanoarchaeota": indication for a broad distribution in high temperature. Syst. Appl. Microbiol. 25, 551-554. (doi:10.1078/07232020260517698)

Huber, R., Stoffers, P., Cheminee, J. L., Richnow, H. H. \& Stetter, K. O. 1990 Hyperthermophilic archaebacteria within the crater and open-sea plume of erupting Macdonald Seamount. Nature 345, 179-181. (doi:10. 1038/345179a0)

Huber, H., Hohn, M. J., Rachel, R., Fuchs, T., Wimmer, V. C. \& Stetter, K. O. 2002 A new phylum of Archaea represented by a nanosized hyperthermophilic symbiont. Nature 417, 63-67. (doi:10.1038/417063a)

Kandler, O. 1994 The early diversification of life. In Early life on earth (ed. S. Bengtson) Nobel Symposium No. 84, pp. 152-160. New York, NY: Columbia University Press.

Kashefi, K. \& Lovley, D. R. 2003 Extending the upper temperature limit of life. Science 301, 934. (doi:10.1126/ science.1086823)

Kopylov, V. M., Bonch-Osmolovskaya, E. A., Svetlichnyi, V. A., Miroshnichenko, M. L. \& Skobkin, V. S. 1993 $\gamma$-Irridation resistance and UV sensitivity of extremely thermophilic archaebacteria and eubacteria. Mikrobiologiya 62, 90-95.

Randau, L., Münch, R., Hohn, M. J., Jahn, D. \& Söll, D. 2005 Nanoarchaeum equitans creates functional t-RNAs from separate genes for their $5^{\prime}-$ and $3^{\prime}$ - halves. Nature 433, 537-541. (doi:10.1038/nature03233)

Schopf, J. W. \& Packer, B. M. 1987 Early Archean (3.3 billion to 3.5 billion-year-old) microfossils from Warrawoona Group, Australia. Science 237, 70-73.

Stetter, K. O. 1982 Ultrathin mycelia-forming organisms from submarine volcanic areas having an optimum growth temperature of $105^{\circ} \mathrm{C}$. Nature 300, 258-260. (doi:10. 1038/300258a0)

Stetter, K. O. 1992 Life at the upper temperature border. In Frontiers of life (ed. J. Tran Thanh Van, K. Tran Thanh Van, J. C. Mounolou, J. Schneider \& C. McKay), pp. 195-219. Gif-sur-Yvette, France: Editions Frontieres.

Stetter, K. O., Thomm, M., Winter, J., Wildgruber, G., Huber, H., Zillig, W., Janecovic, D., König, H., Palm, P. \& Wunderl, S. 1981 Methanothermus fervidus, sp. nov., a novel extremely thermophilic methanogen isolated from an Icelandic hot spring. Zbl. Bakt. Hyg., I. Abt. Orig. C2, $166-178$

Stetter, K. O., Huber, R., Blöchl, E., Kurr, M., Eden, R. D., Fielder, M., Cash, H. \& Vance, I. 1993 Hyperthermophilic archaea are thriving in deep North Sea and Alaskan oil reservoirs. Nature 365, 743-745. (doi:10.1038/ 365743a0)

van Zullen, M. A., Lepland, A. \& Arrhenius, G. 2002 Reassessing the evidence for the earliest traces of life. Nature 418, 627-630. (doi:10.1038/nature00934)

Waters, E. et al. 2003 The genome of Nanoarchaeum equitans: insights into early archaeal evolution and derived parasitism. Proc. Natl Acad. Sci. USA 100, 12 984-12 988. (doi:10.1073/pnas.1735403100)

Woese, C. R. \& Fox, G. E. 1977 Phylogenetic structure of the prokaryotic domain: the primary kingdoms. Proc. Natl Acad. Sci. USA 74, 5088-5090. (doi:10.1073/pnas.74.11. 5088)
Woese, C. R., Kandler, O., M, L. \& Wheelis, M. L. 1990 Towards a natural system of organisms: proposal for the domains Archaea, Bacteria and Eucarya. Proc. Natl Acad. Sci. USA 87, 4576-4579. (doi:10.1073/pnas.87.12.4576)

Zillig, W., Stetter, K. O., Schäfer, W., Janekovic, D., Wunderl, S., Holz, I. \& Palm, P. 1981 Thermoproteales: a novel type of extremely thermoacidophilic anaerobic archaebacteria isolated from Icelandic solfataras. Zbl. Bakt. Hyg., I. Abt. Orig. C2, 205-227.

\section{Discussion}

M. K. Wallis (Cardiff Centre for Astrobiology, Cardiff University, UK). Your abstract mentions hyperthermophiles are tough survivors, including resistance to deepfreezing, making them potentially transported in impact ejecta and still viable when landing on planets and satellites. They also need the ability to survive space radiation. Do they have a general ability to stabilise their genome in spore states or via binding chemicals such as histones?

K. Stetter. The archaeal hyperthermophiles, Pyrococcus furiosus and Thermococcus stetteri, have been tested so far about their resistance against radiation. Although unable to form spores (like all archaea), these organisms indeed exhibit a remarkable resistance against $\gamma$-radiation (2500 Gy). After radiation, the chromosome of Pyrococcus furiosus is fully fragmented, but restored after incubation at $95^{\circ} \mathrm{C}$ (Kopylov et al. 1993; DiRuggiero et al. 1997).

W. R. Taylor (Mathematical Biology, The National Institute for Medical Research, London, UK). The nanoarchaea bacteria sitting on the outside of the larger bacterium remind me of mitochondria (waiting to be let in).

Is there any similarity between the nanobacteria and mitochondria, either in their energy relationship to their host or in the gene-set found in their genome? K. Stetter. No similarity between Nanoarchaeum equitans and mitochondria is evident. Most likely, very much in contrast to mitochondria, Nanoarchaeum obtains its energy from its (Ignicoccus) host.

D. McL. Roberts (Zoology Department, The Natural History Museum, London, UK). As you know, there are many lineages of hyperthermophiles known only from environmental nucleic acid extraction. As uncultured organisms, nothing is known of their metabolism. Can you suggest any fundamental reason why hyperthermophiles should be hydrogenotrophs?

K. Stetter. Not all hyperthermophiles are hydrogenotrophs. For example, there are also sulphur and pyrite oxidizers. However, in hyperthermophiles, hydrogen is a very frequent energy source. This may be due to the presence of hydrogen within volcanic exhalations.

A. E. Walsby (School of Biological Sciences, University of Bristol, UK). Karl Stetter has produced evidence, from Woese's phylogenetic tree, that hyperthermophiles are closest to the root. But returning to my previous comment that the earliest cells would be the simplest, do not hyperthermophiles require histone-like proteins to prevent their DNA melting apart and other sophistications to withstand the high temperature? Might this therefore suggest that the hyperthermophiles were not the earliest forms but evolved from earlier forms that lacked these special characters? 
K. Stetter. This question goes back to the origin of life ('earliest cells'). So far, there are no proofs about the kind of environments (and their temperatures!) inhabited by the earliest life forms. Nobody knows how the first information carrier may have looked like and how ancient histones are. However, in agreement with the geological settings of the early Earth, there should have been very early adaptations in order to colonize high temperature niches (like hot vents). In surviving the heavy meteorite bombardment, those high temperature organisms could have given rise to the three domains of life, as evidenced by Woese's phylogenetic tree. Therefore, by impact selection the last common ancestor of the present life forms most likely could have been a hyperthermophile. Its adaptation to high temperatures may have occurred much earlier, however.
J. J. McFadden (Biological Sciences, University of Surrey, $U K)$. Is the nanoarchaeota a transport parasite? Is the nanoarchaeota infectious?

K. Stetter. These are crucial questions for a deeper understanding of the Nanoarchaeum-Ignicoccus system, which are still under investigation. Highly unexpected, there are only very few transporter genes in the $N$. equitans genome. $N$. equitans is infectious to its host, Ignicoccus sp. Although very rarely, we were able to reconstitute the system: single cells of two different components; the two single cells were combined and a coculture was obtained by cultivation. We were never able to detect the cells of $N$. equitans inside its Ignicoccus host. Therefore, the ways of supply of life-supporting cell components in $N$. equitans are still unknown. 